\title{
PENGENALAN INTERNET OF THINGS (IOT) UNTUK PENINGKATAN SOFTSKILL PADA SISWA SMA N 5 TEGAL
}

\author{
Ida Afriliana ${ }^{* 1}$, Eko Budihartono ${ }^{2}$, Yerry Febrian $\mathrm{S}^{3}$ \\ 1,2,3 Program Studi Teknik Komputer, Politeknik Harapan Bersama \\ e-mail:*11idaafriharahap@gmail.com, ${ }^{2}$ tara.niscita@gmail.com
}

\begin{abstract}
Abstrak
Perkembangan teknologi yang begitu pesat di berbagai bidang, sangat mempengaruhi kehidupan manusia. Teknologi yang bebas nilai sehingga bisa diimplementasikan di berbagai nilai kehidupan. Ponsel sudah bukan barang yang mewah untuk dimiliki, tetapi sudah menjadi kebutuhan dalam kehidupan manusia. Untuk itu semua lapisan masyarakat harus dapat mengikutialur perkembangan teknologi ini.

SMA N 5 Tegal adalah Sekolah Menengah Atas yang berlokasi di Jl. Kali Kemiri II Margadana Tegal, merupakan salah satu SMA Negeri yang baik di Kota Tegal karena lulusannya dibekali hardskill dan softskill. Dengan ketrampilan tersebut diharapkan lulusan SMA N 5 Tegal dapat mengimplementasikan dalam kehidupan sehari-hari seperti yang tertuang pada misi SMA N 5 yakni "TERWUJUDNYA GENERASI PENERUS BANGSA YANG BERMUTU DAN BERAKHLAK MULIA SERTA MAMPU MENJADI PELOPOR BAGI KEMAJUAN MASYARAKAT DAN NEGARA".

Untuk membekali siswa/i dalam pengetahuan teknologi maka pengabdian masyarakat perlu dilakukan dengan tujuan memperkenalkan Internet of Things (IoT) untum meningkatkan softskill siswa SMA N 5 Tegal. Melihat fenomena saat ini hampir semua benda dapat kita gunakan seperti yang kita inginkan hanya dengan menekan tombol pada ponsel. Benda-benda yang "cerdas" karena pada benda tersebut telah dilengkapi dengan alat-alat teknologi sesuai dengan kebutuhan manusia. Inilah konsep pada Internet of Things yakni benda-benda yang cerdas dengan dilengkapi tekologi.
\end{abstract}

Kata kunci-Teknologi, Internet of Things, Teknologi SMA N 5 Tegal

\section{PENDAHULUAN}

Pada era globalisasi seperti sekarang ini kemajuan teknologi berkembang sangat pesat dan membantu manusia berinteraksi satu sama lain tanpa dibatasi oleh jarak dan waktu. Kemudahan yang diberikan oleh teknologi mencakup berbagai aspek kehidupan, mulai dari bisnis hingga pendidikan. Teknologi sangat berperan penting dalam bidang pendidikan.

SMA N 5 Tegal adalah Sekolah Menengah Atas yang berlokasi di Jl. Kali Kemiri II Margadana Tegal, merupakan salah satu SMA Negeri yang baik di Kota Tegal karena lulusannya dibekali hardskill dan softskill. Sesuai dengan Visi SMA N 5 Tegal yakni "TERWUJUDNYA GENERASI PENERUS BANGSA YANG BERMUTU DAN BERAKHLAK MULIA SERTA MAMPU MENJADI PELOPOR BAGI KEMAJUAN MASYARAKAT DAN NEGARA"

Adapun misi SMA N 5 Tegal antara lain:

1. Mengusahakan kegiatan belajar menggajar yang intensif untuk meningkatkan kemampuan akademik dan penalaran siswa.

2. Meningkatkan kedisiplinan segenap warga sekolah,baik siswa,guru,karyawan dan pimpinan sekolah. 
3. Menciptakan suasana sekolah yang sejuk, religius, demokratis, penuh semangat kekeluargaan dan kebersamaan.

4. Meningkatkan kualitas kegiatan ekstra kurikuler untuk memberi bekal ketrampilan dan pembentukan watak pribadi yang mandiri dan bermutu.

5. Meningkatkan kualitas dan kuantitas sarana dan prasarana sekolah untuk membantu pencapaian pembelajaran dan pendidikan.

6. Menghasilkan lulusan/tamatan yang memiliki daya saing tinggi agar dapat melanjutkan ke jenjang pendidikan yang lebih tinggi atau memasuki dunia kerja dan membantu masyarakat.

7. Mampu meraih predikat juara dalam setiap event lomba, kejuaraan atau kompetisi yang diikuti di tingkat Kota Tegal dan Provinsi Jawa Tengah di bidang Olahraga, Seni, Keaggamaan dan Karya Ilmiah.

8. Meningkatkan kualitas manajemen pengelolaan pendidikan sekolah dengan mengedepankan prinsip demokrasi,transparansi dan partisipasi dari segenap warga secara proporsional, baik dari dewan guru, karyawan dan komite sekolah.

Untuk tercapainya visi tersebut maka proses pembelajaran pada SMA N 5 Tegal memegang peranan yang penting. Siswa harus dapat memiliki hardskill dan softskill karena diharapkan setelah lulus akan menjadi sumber daya manusia yang memiliki daya saing tinggi untuk melanjutkan ke jenjang pendidikan yang lebih tinggi walaupun tidak menutup kemungkinan bagi lulusannya untuk memasuki dunia kerja. Oleh karena itulah Softskill sangat dibutuhkan agar lulusannya memenuhi persyarakat bagi stakeholder.

Seiring perkembangan teknologi informasi yang sangat pesat maka proses pembelajaran dapat dilakukan lebih baik, dengan mengimplementasikan teknologi dalam proses pembelajaran. Proses Pembelajaran dengan tatap muka adalah proses pembelajaran yang sering dilakukan oleh para pengajar, tetapi ada kalanya siswa juga dituntut untuk aktif dalam proses pembelajaran atau biasa disebut Student Center Learning atau biasa disingkat dengan SCL. Dengan perkembangan teknologi yang sangat cepat maka internet menjadi hal yang sangat penting bagi kehidupan manusia.

Memusuki era milenia, gadget sudah bukan barang mewah lagi tetapi menjadi kebutuhan yang menunjang kehidupan manusia di segala bidang, yang biasa dikenal dengan istilah Internet of Things(IoT) yakni benda-benda atau alat alat yang cerdas yang dapat berguna untuk kehidupan manusia. Oleh karena itu pengabdian masyarakat ini memberikan pengenalan tentang Internet of Things (IoT) kepada siswa/i kelas 12 SMA N 5 Tegal.

\subsection{Sasaran Kegiatan PKM}

\section{METODE}

Kegiatan pengabdian masyarakat yang dilakukan ke sekolah-sekolah kejuruan merupakan salah satu sasaran bagi prodi DIII Teknik Komputer, dimana setiap kali pengbdian masyarakat, tidak dapat semua siswa terakomodir dalam kegiatan ini, tetapi dilakukan secara berkala dengan jumlah kuota tertentu.

Khalayak sasaran pengabdian masyarakat kali ini pengenalan Internet of Things (IoT) diberikan kepada siswa /i SMA N 5 Tegal khususnya kelas 12 IPA. Pengenalan materi diberikan dengan pemberian materi selama 1 jam (60 menit) kemudian dilanjutkan dengan praktek alat sensor sederhana dan penggunaannya. Dalam hal ini metode ceramah, praktek dan tanya jawab digunakan pada pengbdian masyarakat ini.

\section{2 Metode Kegiatan}

Metode kegiatan pengabdian masyarakat kali ini dilakukan oleh 3 dosen dan beberapa mahasiswa peserta PKM yang turun langsung di penyampaian materi dan 
pemdampingan. Kegiatan berupa pelatihan tentang pengenalan tentng internet of things, alat yang digunakan dan softwarenya.

Penyampaian materi dilakukan selama 60 menit dan kemudian dilanjutkan dengan praktek Praktek menggunakan sensor suhu dengan softwarenya didemokan kepada siswa/i. Dan praktek ini dilakukan dengan pendmpingn dosen dan mahasiswa.

Selain praktek dilakukan kuis berhadiah untuk memberikan apresiasi kepada siswa/i yang telah berperaan aktif dalam PKM ini.

\section{3 Tahapan Kegiatan PKM}

\section{3.1 Persiapan}

Sebelum kegiatan dilaksanakan maka dilakukan persiapan-persiapan sebagai berikut :

(1) Melakukan studi pustaka tentang materi Internet of Things; (2) Mempersiapkan kebutuhan untuk pelatihan tentang praktek IoT ; (3) Menentukan waktu pelaksanaan dan lamanya kegiatan pengabdian masyarakat.

\section{3.2 Pelaksanaan Kegiatan}

Adapun kegiatan IbM dalam bentuk pelatihan ini dilaksanakan selama satu hari pada hari Jumat dan Sabtu, tanggal 26-27 Januari 2018, waktu dari 08.00 WIB s.d selesai bertempat di SMK Assalafiyah kota Tegal. Pelatihan ini dilakukan di Aula SMA N 5 kota Tegal. Dengan difasilitasi dengan modul dan pendampingan 1 mahasiswa mendampingi 2-3 siswa. Pelaksanaan praktek dilakukan dengan baik dan berjalan lancar.

\section{3.3 Evaluasi Kegiatan}

Untuk memncapai target tujuan pelatihan ini, maka pada evaluasi kegiatan peserta diberikan kuis tentang materi Iot dan alat yang diparktekkan. Untuk pendalaman materi selain membuat satu obyek, para siswa juga diberikan kesempatan untuk bertanya tentang alat yang dipraktekkan yakni berbagai macam sensor. Disini diberikan materi-materi dasar tentang bentuk-bentuk dasar pada sensor. Diharapkan setelah belajar dapat menjelaskan kembali tentang benda-benda yng dapat cerdas dalam kehidupan manusia dan memotivasi siswa untuk mempelajari lebih lanjut ke jenjang IoT berikutnya, bukan hanya mengenal tetapi mendalami sampai cara pembuatan alat yang berbasis IoT.

\subsection{Kegiatan Pelatihan}

\section{HASIL DAN PEMBAHASAN}

Pada pengabdian masyarakat di SMA N 5 Tegal ini diberikan materi dasar pada Internet of Thinga. Alasan mengapa materi ini yang diberikan kepada siswa SMA N 5 adalah meningkatkan softskill para siswa terutama siswa jurusan IPA.

Materi yang disampaikan pada kegiatan pengabdian masyarakat oleh dosen DIII prodi komputer adalah sebagai berikut;

(a) Konsep IoT.

(b) Pengenalan Tools dalam IoT.

(c) Praktek mengimplementasikan sensor suhu dengan software .

(d) Tanya jawab dan diskusi.

Pada Gambar 1 memperlihatkan proses kegiatan pelatihan yang diikuti oleh para peserta kegiatan. Pada kegiatan ini proses pemberian materi dilakukan oleh tim pelaksana PKM yang terdiri dari Dosen dan mahasiswa sebagai tim pembantu teknik pelaksanakan PKM. 
Gambar 2 merupakan foto bersama baik pelaksana PKM maupun peserta PKM didampingi oleh guru-guru SMA N 5 Tegal.

Software dan pengenalan salah satu alat sensor ,yakni sensor suhu menjadi fokus pada PKM kali ini. Hal ini melihat berkembangnya teknologi komputer, yang terutama pada perangkat lunak, mau tidak mau kita juga harus mengikuti perkembangannya.

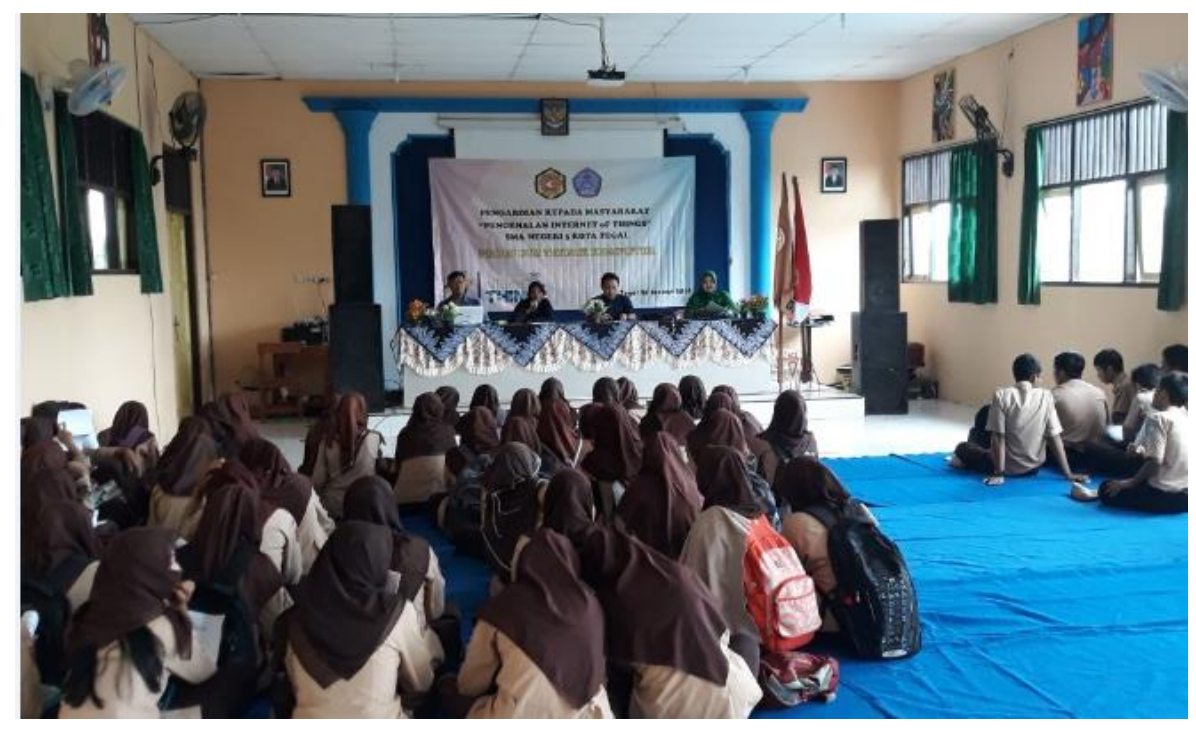

Gambar 1 Pemberian materi kepada peserta

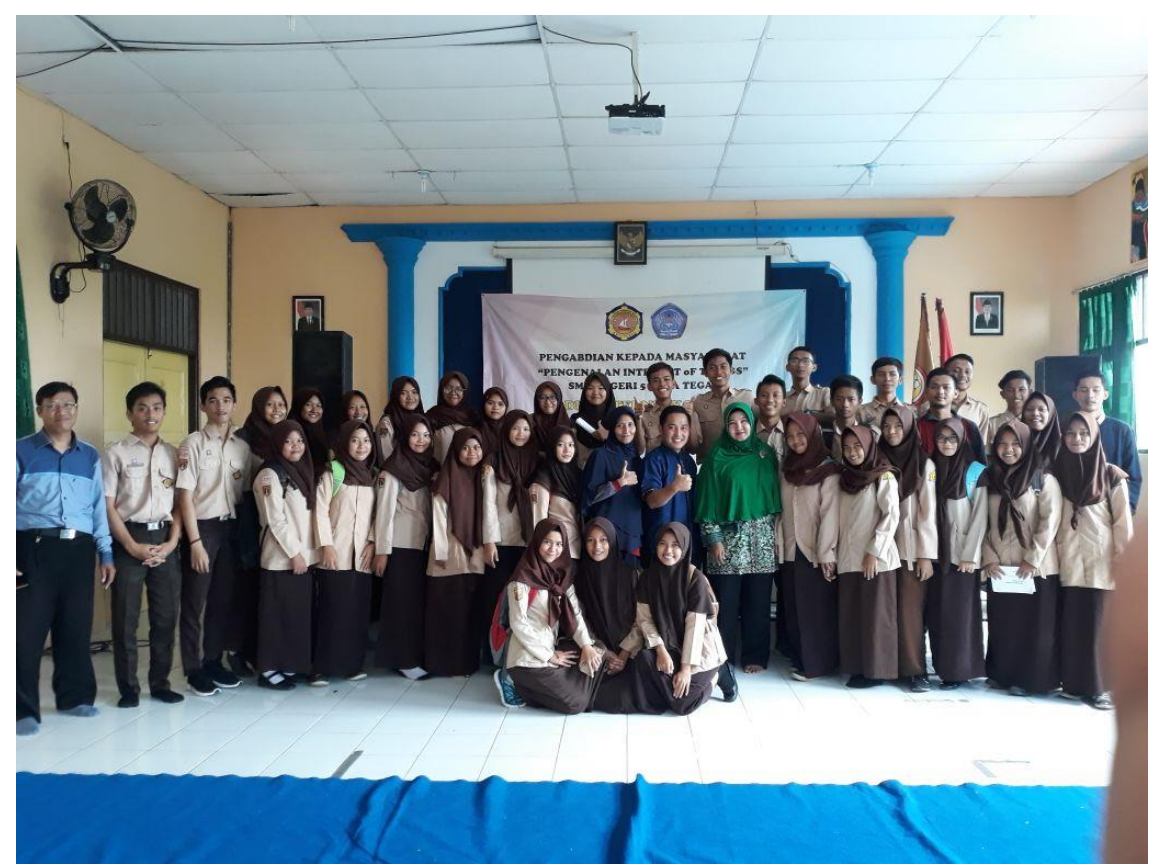

Gambar 2 Foto bersama peserta PKM 


\subsection{Pendampingan Program}

Dalam kegiatan pelatihan diperlukan pendampingan supaya peserta benar-benar paham dalam mengapilikasikan materi. Yaitu dengan praktek dibimbing sampai menyelesaikan suatu project.

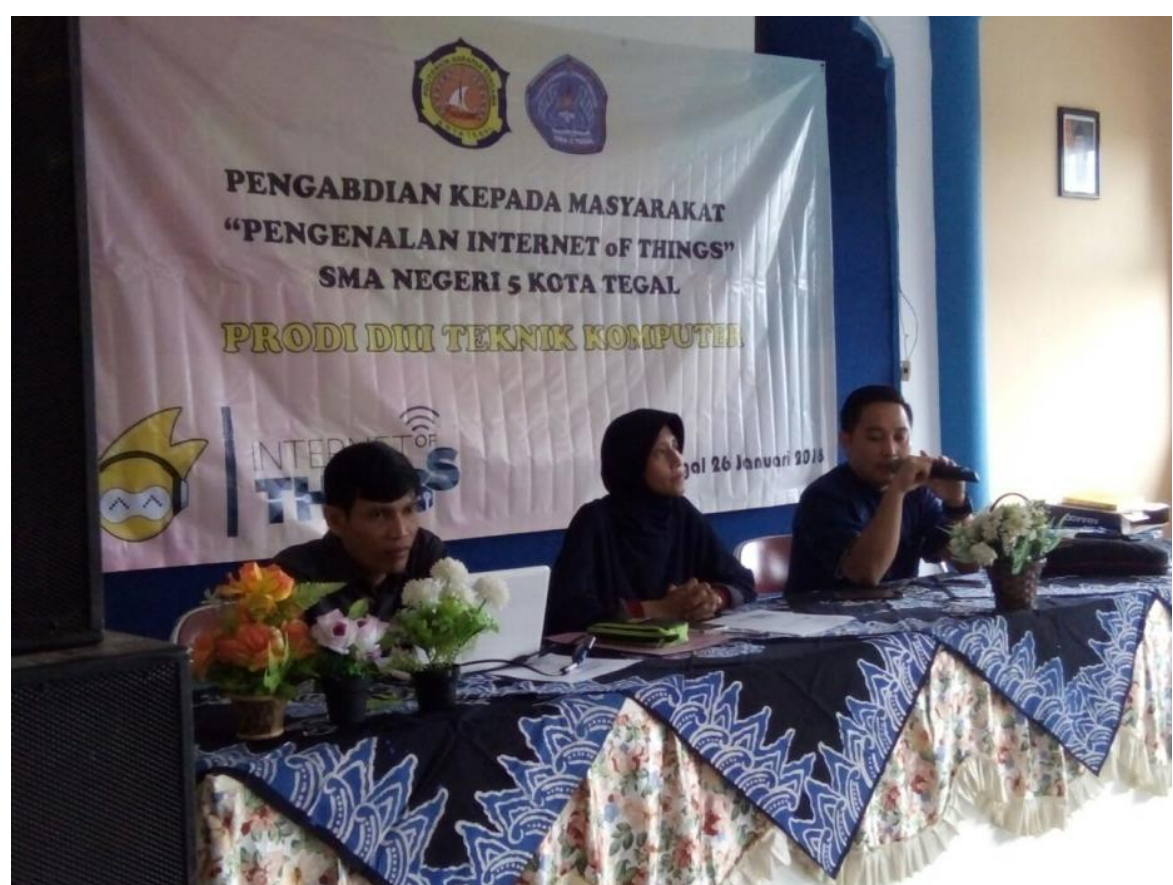

Gambar 3. Proses Pendampingan peserta kegiatan

Pada Gambar 3 memperlihatkan kegiatn pemberian materi saat PKM, kemudian dilakukan praktek langsung oleh pemateri dengan pendampingan dilakukan oleh tim pelaksana PKM dan Mahasiswa. Pada proses pendampingan ini peserta kegiatan diarahkan dan dibimbing langsung face-to face sehingga harapannya dapat lebih optimal dalam proses.

Pada proses pendampingan ini terlihat bahwa hampir seluruh siswa sangat antusias mendapatkan materi ini, karena memang ini materi yang baru pertama kali mereka dapatkan. Pemberian kuis berisi pertanyaan tentang materi yang dipraktekkan, yakni tentang sensor suhu dan software yang digunakan.

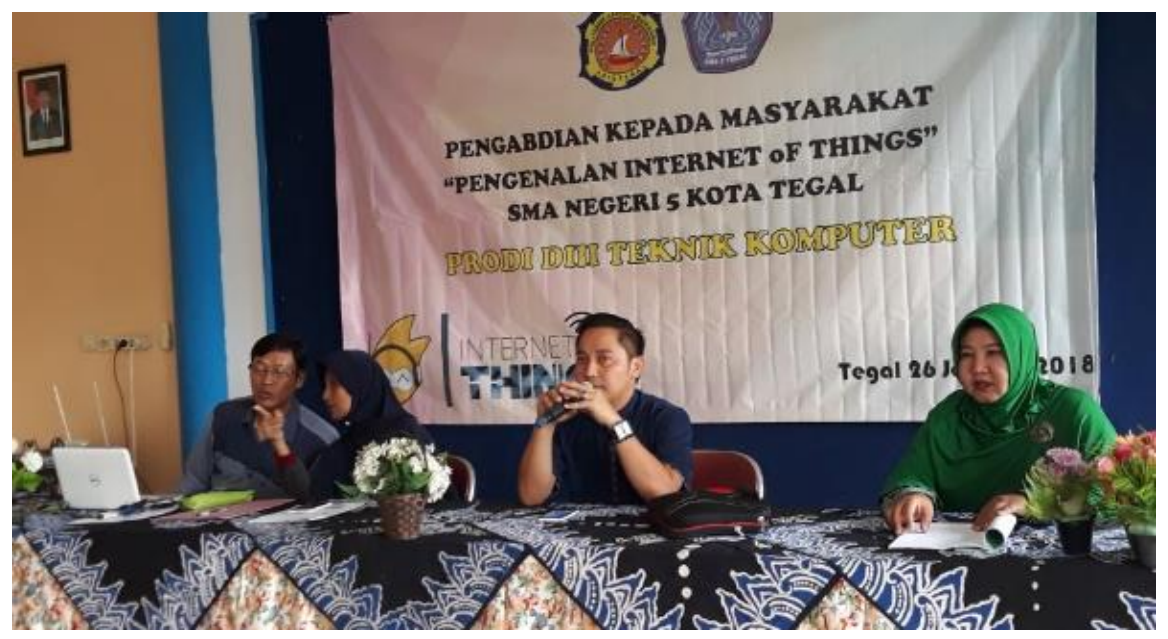

Gambar 4 Proses Pendampingan peserta kegiatan 


\subsection{Capaian Kegiatan}

PKM ini menfokuskan pada Pengenalan IoT, dimana ini merupakan hal yang baru bagi siswa-siswi SMA N 5 Tegal. Berdasarkan hasil wawancara dan pengamatan langsung bahwa siswa belum pernah mendapatkan materi ini,s ementara perkembangan teknologi sangat pesat di era milenia ini.

Dengan metode presentasi dan diskusi serta praktek dan pendampingan terhadap peserta kegiatan, pelatihan dilaksanakan dengan tujuan output yang dihasilkan pada pelatihan ini peserta kegiatan mempunyai ilmu yang baru dan dapat mengetahui mengenai perkembangan teknologi khususnya multimedia.

\section{KESIMPULAN}

Dari kegiatan pelatihan ini peserta jadi lebih mahir dalam hal desain grafis khususnya dalam penguasaan CorelDraw dengan dibuktikan dengan faktor faktor berikut ini :

1. Memberikan pengetahuan ilmu baru bagi siswa SMA N 5 Tegal tentang perkembangan teknologi saat ini khususnya IoT.

2. Meningkatkan ketrampilan softskill siswa SMA N 5 Tegal dalam menerapkan IoT dalam kehidupan sehari-hari.

\section{SARAN}

Mengingat besarnya manfaat kegiatan pengabdian masyarkat ini, maka selanjutnya perlu adanya pelatihan sebagai tindak lanjut peningkatan softskill siswa tentang teknologi dan dilakukan pendampingan perlu dilakukan selama pelatihan dan demo project.

\section{UCAPAN TERIMA KASIH}

Terima kasih kepada Pusat Penelitian dan Pengabdian Masyarakat (P3M) Politeknik Harapan Bersama Tegal yang telah membiayai kegiatan PKM yang telah dilaksanakan ini pada tahun anggaran 2018.

\section{DAFTAR PUSTAKA}

[1] Admin.2008. Pengertian software (Perangkat Lunak)

Komputer.(online),http://belajar-komputer-mu.com, diakses 15 Desember 2011.

[2] Arief Marwanto (2017). Seminar Internet of Things for better lives, Program Pasca Sarjana Teknik Elektro,UNISULA

[3] Internet Of Things, Panduan Lengkap membuat Internet of Things, Oktober,2016

[4] Cisco IoT http://www.cisco.com/web/solutions/trends/iot/overview.html

[5] Windows http://www.microsoft.com/en-us/server-cloud/internet-of-things.aspx

[6] Intel https://software.intel.com/en-us/iot/home 